Illinois State University

ISU ReD: Research and eData

Theses and Dissertations

$4-10-2020$

\title{
The Effects Of Nutrition Smartphone Applications On Parents' Grocery Shopping And Meal Planning Behaviors
}

Lacey Bertram

Illinois State University, Ibertra@ilstu.edu

Follow this and additional works at: https://ir.library.illinoisstate.edu/etd

Part of the Human and Clinical Nutrition Commons

\section{Recommended Citation}

Bertram, Lacey, "The Effects Of Nutrition Smartphone Applications On Parents' Grocery Shopping And Meal Planning Behaviors" (2020). Theses and Dissertations. 1250.

https://ir.library.illinoisstate.edu/etd/1250

This Thesis is brought to you for free and open access by ISU ReD: Research and eData. It has been accepted for inclusion in Theses and Dissertations by an authorized administrator of ISU ReD: Research and eData. For more information, please contact ISUReD@ilstu.edu. 


\section{THE EFFECTS OF NUTRITION SMARTPHONE APPLICATIONS ON PARENTS' GROCERY SHOPPING AND MEAL PLANNING BEHAVIORS}

\section{LACEY BERTRAM}

41 Pages

The purpose of this experimental research study was to determine the effects that nutrition smartphone applications, specifically grocery list generation applications, have on parents' overall grocery shopping experience and meal planning behaviors for their families. The prevalence of adolescent obesity in today's society has significantly increased to an alarming rate and family mealtimes together have decreased. Family mealtimes together can impact a child's weight status and future health outcomes. A total of 10 participants investigated and classified the aspects in a nutrition smartphone application that were beneficial to meal planning and grocery shopping. The findings indicated that a nutrition smartphone application that has low time consumption and provided a grocery list based off of food preferences incorporated into the design was more likely to benefit parents' meal planning and grocery shopping behaviors. The results also indicated that while using the nutrition smartphone applications, families ate an evening meal at least five times together. In conclusion, a smartphone application that is beneficial to parents' overall meal planning for their families can possibly increase family mealtimes spent together.

KEYWORDS: grocery shopping, meal planning, family mealtime, childhood obesity, smartphone application, nutritional meals, adolescent health outcomes 
THE EFFECTS OF NUTRITION SMARTPHONE APPLICATIONS ON PARENTS'

GROCERY SHOPPING AND MEAL PLANNING BEHAVIORS

LACEY BERTRAM

\author{
A Thesis Submitted in Partial \\ Fulfillment of the Requirements \\ for the Degree of \\ MASTER OF SCIENCE \\ Department of Family \& Consumer Sciences \\ ILLINOIS STATE UNIVERSITY
}

2020 
(C) 2020 Lacey Bertram 
THE EFFECTS OF NUTRITION SMARTPHONE APPLICATIONS ON PARENTS'

GROCERY SHOPPING AND MEAL PLANNING BEHAVIORS

LACEY BERTRAM

COMMITTEE MEMBERS:

Julie Schumacher, Chair

Amy Bardwell

Jennifer Barnes 


\section{ACKNOWLEDGMENTS}

The path toward this thesis has been challenging yet empowering and memorable.

Gratitude is necessary to the special people who have encouraged, supported and stuck with me during the completion of this study. I am tremendously fortunate to be a student in the dietetics program at Illinois State University and to have professors that push me towards higher potential. I would like to begin by expressing my appreciation to my committee chair, Dr. Julie

Schumacher. Thank you for your continuous support and guidance during this unknowing project. Your expertise has taught me more than I could have imagined during this study. I also want to give gratitude to my co-chairs Dr. Jennifer Barnes and Dr. Amy Bardwell. Thank you for your statistical intelligence, research knowledge and kindness to keep pushing me. This work would not have been possible without the support, professional insight and guidance from my committee. For that I am grateful.

I would like to continue to share my gratitude to Cecily Martinez, Jessica Brand, Alyssa Laing and Jared Lyons who have continuously supported me and kept encouraging me through the difficult yet exciting milestones that this study has brought. You all have kept me motivated to remember my goals and persevere through the struggles.

Lastly, I would like to thank my family for supporting me throughout my academic career. I would not be writing this thesis in my graduate career without your encouragement and reassurance. I have no valuable words to express my gratitude, but my heart is full of the love and support that I have received from each person in this journey. I am blessed to have the professionals, family and friends in my life that made this possible. Thank you all.

L.B. 


\section{CONTENTS}

Page

ACKNOWLEDGMENTS

$\begin{array}{lll}\text { TABLES } & \text { iii }\end{array}$

CHAPTER I: THE EFFECTS OF NUTRITION SMARTPHONE APPLICATIONS ON

PARENTS' GROCERY SHOPPING AND MEAL PLANNING BEHAVIORS 1

Introduction $\quad 1$

Methodology 5

Applications $\quad 5$

$\begin{array}{ll}\text { Sample } & 7\end{array}$

$\begin{array}{ll}\text { Sample Procedure } & 7\end{array}$

$\begin{array}{ll}\text { Participant Survey } & 9\end{array}$

$\begin{array}{lr}\text { Statistical Analysis } & 10\end{array}$

$\begin{array}{ll}\text { Results } & 10\end{array}$

$\begin{array}{lr}\text { Total Participants Demographics } & 10\end{array}$

$\begin{array}{ll}\text { Application Question Correlations } & 10\end{array}$

Discussion $\quad 11$

Smartphone Application Effects on Grocery Shopping and Meal Planing 11

$\begin{array}{lr}\text { Increased Family Mealtimes } & 12\end{array}$

$\begin{array}{ll}\text { Grocery List Generation } & 13\end{array}$

$\begin{array}{ll}\text { Food Preferences } & 14\end{array}$

$\begin{array}{ll}\text { Limitations } & 15\end{array}$

$\begin{array}{ll}\text { Conclusion } & 17\end{array}$ 
$\begin{array}{ll}\text { Parents and Meal Planning } & 22\end{array}$

Lack of Meal Planning Results in Food Waste in Families 25

$\begin{array}{ll}\text { Family Mealtimes } & 26\end{array}$

$\begin{array}{ll}\text { Parent Grocery Shopping Behaviors } & 29\end{array}$

Home-Cooked Family Meals and Children's Health 31

$\begin{array}{ll}\text { Conclusion } & 33\end{array}$

$\begin{array}{ll}\text { REFERENCES } & 35\end{array}$

APPENDIX A: SMARTPHONE APPLICATION CRITERIA 40

APPENDIX B: SMARTPHONE APPLICATION PARTICIPANT SURVEY 41 


\section{TABLES}

Table

Page

1. Participant Demographic Information

2. Bivariate Correlation Test Results

19

3. Application Survey Results

20 


\section{CHAPTER I: THE EFFECTS OF NUTRITION SMARTPHONE APPLICATIONS ON PARENTS' GROCERY SHOPPING AND MEAL PLANNING BEHAVIORS}

\section{Introduction}

The prevalence of childhood and adolescence obesity are increasing at an alarming rate and are influenced by multiple factors. Genetics, family culture, environment, and socioeconomic factors can all be included in this epidemic. The alarming number of 124 million children can be considered part of the childhood obesity epidemic. Nearly one in five children are included in the overweight or obese category (Kim \& Lim, 2019). Based on this literature it can be inferred that an early intervention during adolescents' growth is needed to improve childhood obesity. Children that become overweight at an earlier age remain overweight and will maintain obesity for a longer period of time (Yakovenko, Henn, Bettendorf, Zelinska, Soloviova, Hoffmann \& Grulich-Henn, 2019). Research suggests that children who become overweight at a young age have a greater likelihood of remaining overweight throughout their adult lives. The prevalence of adolescent obesity has jumped from 11.6\% in 2008 to $17.3 \%$ in 2017 (Kim et al., 2019). This present situation of childhood obesity is so alarming that literature supports that if levels of obesity are not significantly reduced, the current generation of American adolescents will see shorter lives than their parents (Olshansky, Passaro, Hershow, Layden \& Carnes, 2005). This increasing rate of obesity is shocking for future health outcomes for adolescents.

Dietary and health related factors that are present in a child's life can determine their adult health in many ways. Children experience an increased adiposity level when their weight begins to climb. These increased adiposity level increases the chances of developing comorbidities later in life (Kim et al., 2019). These comorbidities can include diabetes, hypertension, and cardiovascular disease. Dietary practices within the individual family during 
critical growth periods are crucial for adolescent development. Unhealthy dietary practices in adolescence can affect physical and cognitive development that can have consequences later in the child's life. These dietary practices begin within the family environment. Literature supports that positive dietary behaviors and family support through regular mealtimes, eating at home together as a family, and home cooked meals with proper portion sizing have the most beneficial effects on childhood future health outcomes (Kim et al., 2019). Children carry traditions and specific practices from their parents into their own lives as they age. When discussing parent's role in the epidemic of childhood obesity, research states that the family's role is central for the learned behaviors of the children. The products consumed within the family can remarkably shape overconsumption behaviors in the children (Richins \& Chaplin, 2015). The parent's health behaviors that they teach to the children are the basic framework for the growth of the child.

The parent's role in the future health outcomes of the children is widely supported by literature. Eating family meals together largely impacts more than a child's health. Research shows that frequent family meals are associated with improved dietary intake, decreased likelihood of disordered eating, improved academic status in adolescents and lower level of substance abuse (Walton, Kleinman, Rifas-Shiman, Horton \& Gillman, 2016). The role of a homecooked family meals is distinctly correlated with child development. Family mealtimes together have decreased from 1996 to 2008 and have only kept decreasing (Walton et al., 2016). With the rapid increase of childhood obesity and the decline of family meals eaten together, there could potentially be a correlation of homecooked family meals and future health outcomes of children. This decrease in family meals could be correlated to busy family schedules between sporting activities, work, school and multiple children agendas. When a parent has multiple schedules to plan around, family mealtime could be decreased. 
When family's schedules become busier, the likelihood of pre-planning meals could decrease due to decrease of available time. Looking at current human behaviors could help determine what tools would benefit people with time efficient tasks. Over 3.5 billion people worldwide have a smartphone. Three quarters of individuals use their smartphone to access the internet and to complete common daily tasks (Handley, 2019). If parents battle with time for planning family meals and their phones are already with them, then the smartphone could be used to meal plan efficiently. Technology is utilized for communication, work, transportation and many more tasks that humans tackle every day. Research supports that when parents are stressed with a busy schedule, they are less likely to plan a meal for their family and opt for quick, unhealthy snacks (Alm \& Olsen, 2017). When families become busier and parent's stress becomes heightened, family mealtimes together could suffer. If parents already have their smartphone device with them, there should be an efficient and effective way to use it to increase the likelihood of eating meals together as a family. The rise in family mealtimes could directly correlate with the children's future health outcomes.

The prevalence of childhood obesity in today's society is alarming. With the correlation of childhood obesity rising and family mealtimes declining, it fosters the need to figure out how to improve the likelihood of families eating a meal together at home (Walton et al., 2016). Current literature does not explore the methods most beneficial to parents for preparing meals at home. Therefore, this research will seek to investigate this specific topic to fill the research gap. The purpose of this experimental research study was to determine what effects a nutrition smartphone application has on parents' meal planning and grocery shopping behaviors for their families. 
The independent variables are the nutrition smartphone applications. The dependent variables are described as the family's mealtimes eaten together. The variables in this study are used to determine if the smartphone applications will increase mealtimes eaten together as a family.

The objective of this study was to fill the gap of literature by determining if a smartphone application has an effect on parent's meal planning and grocery shopping behaviors. It was hypothesized that a smartphone application that is beneficial to a parent's grocery shopping and/or planning of meals will increase the times that a family eats the evening meal together. It was also hypothesized that a smartphone application will benefit a parent's grocery shopping and/or meal planning if the application considers budget, food preferences, and generates a grocery list. Lastly, it was hypothesized that a smartphone application that generates a grocery list will allow parents to stay within their budget.

The significance of this research study is that it highlights the features that are beneficial in a smartphone application to parents' grocery shopping and meal planning for their families. The results from this study will be useful in the future for a new nutrition smartphone application development. The findings can also be helpful for nutrition professionals to be able to provide a resource for their clients for meal planning and grocery shopping. This study will be beneficial to parent's meal planning for their family and could benefit adolescents' future health outcomes. This study will also fill a research gap on the benefits of smartphone applications for family mealtimes. 


\section{Methodology}

\section{Applications}

To determine which three applications would be utilized by the participants, the study utilized the Apple and Android application store to search the keywords: grocery shopping, grocery list, recipes, coupons and nutrition. Eleven applications were generated from the search that fit the keywords. Each of the eleven applications were tested individually in the smartphone application criteria questionnaire (Appendix A). The questions from Appendix A were created to simulate the aspects that would be included in the researcher's model smartphone application. The three applications that had the most categories checked "yes" on the smartphone application criteria questionnaire, were introduced to participants to be utilized for their meal planning and grocery shopping. Applications were rejected for the study if they were grocery store specific, if they cost money to download and if they were not grocery shopping and meal planning specific. The three top applications that had the greatest questions answered "yes" were: Mealime Meal Plans and Recipes, Shopping List Ease - Grocery List and Grocery - Smart Shopping List. These applications were chosen to share with participants for the exploration study.

Shopping List Ease - Grocery is one of the applications that participants utilized within this study. This application focuses on the organization of a grocery list. This application allows users to share the grocery list that is created with others so that multiple family members can add ingredients. The user can organize food items, recipes and coupons however they would like. Within the application, users can input prices of each item, which tallies into a total. The individual is able to determine how much will be spent on all of the items on the list. If location services are running, this application will also send the user a reminder notification when they enter a grocery store. This application does not account for user food preferences. 
Grocery - Smart Shopping List is another application that the participants utilized. This application focuses on creating a grocery list. This application allows individuals to organize the food products that they need into specific categories. Within the categories, individuals can also select the exact quantity of the item needed. Grocery gives users recipe options that can be selected. From the recipe that is selected, the food items needed are added to a grocery list. The grocery list that is created within the application can be sent to multiple different smart devices, so an individual has easy access to it wherever they are. The user can also add food items that they already have within their homes to the grocery list so that they do not purchase double food items. The application will notify the user if an item is expected to expire as well. There are no options to select certain food preferences for recipes in this application. If an individual has an allergy, the application will not filter recipes for them.

Mealime Meal Plans and Recipes was the third application that the participants utilized. This application is free to download and is useful for individuals needing customized recipe ideas. The application allows individuals to specify what recipes they would like to have. If an individual has celiac disease, allergies, low carbohydrate, vegetarian, certain food preferences and more, this application will filter certain recipes for them. This application shows full instructions for each recipe with the specific cooking utensils needed as well. Once the individual decides each recipe they would like to prepare for the week, this application gives a grocery list for the total ingredients needed. Each recipe also has nutrient information that is helpful if the user is tracking their nutrition intake. There is an upgrade option that individuals can choose for more advanced options within the application. 


\section{Sample}

Individuals were asked to participate in this experimental study through a Facebook post. Participants were able to enroll in this experimental study if they lived in McLean county, Illinois and if they had at least one child enrolled in Kindergarten - 8th grade. This grade range was chosen to ensure that the parents were still responsible for the child's scheduling and meal planning. Participants who did not have children were excluded from this study because the study investigated parents' meal planning behaviors for their families. Participants who did not live in McLean county were also excluded from the study because the incentive for completing the study was a fresh fruit and vegetable produce bag that had to be picked up in McLean county. Participants enrolled in the study by entering their email address on the original Facebook post that introduced the study. The participants then received an initial email further introducing the study. Each of the three applications were evaluated by parents across the span of three weeks and comparing their preferences with their meal planning and grocery shopping behaviors. The three applications were chosen by a set of criteria, such as considering food preferences, organization of food items, and grocery list generation with specific quantities (Appendix A).

\section{Sample Procedure}

This study was a total of three weeks and invited the participants to use and provide feedback on a new application each week. The 'week' began on Wednesday and conclude the following Tuesday. This timeframe gave the participants time to use the application for their meal and grocery planning before the participants went to the store. The following instructions were divided into the three weeks. The participants were asked to follow each week's plan, use an assigned application, and utilize the application as often as they could. The participants were asked to become familiar with the application to determine if the features within the application 
were beneficial to their meal planning and grocery shopping. At the end of each week (Tuesday), the participants took a short survey (Appendix B) about their experiences with the application. The survey was emailed to them at the email address provided on Sunday prior to the end of the week to give the participants a few days to complete the survey.

The participants were divided into three groups using an excel spreadsheet. All of the participants' emails were entered into the spreadsheet and randomly sorted into three groups using the data randomization function. Each group utilized a different application each week, for a total of 21 days for the three applications. This time was allotted so that the participants had enough time to fully investigate the applications. Differentiating the application order prevented participant biased. Group 1 began with application \#1, then switched to application \#2 on week two, and ended with application \#3 on week three. Group 2 began with application \#2, then switched to application \#3 on week two, and ended with application \#1 on week three. Group 3 began with application \#3, then switched to application \#1 on week two, and ended with application \#2 on week three.

The following were instructions for Group 1 during the experimental study; Group 2 and 3 were modified per application assignment.

Week 1

Download the smartphone application Grocery - Smart Grocery List. Utilize the application for your meal planning and grocery shopping. For the best experience, try to use the application while you are creating your grocery list, while you are at the grocery store and during meal preparation. At the end of week one, take the post application survey that will be sent via email.

Week 2 
Download the smartphone application Mealime. Utilize the application for your meal planning and grocery shopping. For the best experience, try to use the application while you are creating your grocery list, while you are at the grocery store and during meal preparation. At the end of week two, take the post application survey that will be sent via email.

\section{Week 3}

Download the smartphone application Shopping List Ease - Grocery. Utilize the application for your meal planning and grocery shopping. For the best experience, try to use the application while you are creating your grocery list, while you are at the grocery store and during meal preparation. At the end of week three, take the post application survey that will be sent via email.

\section{Participant Survey}

A survey was created for participants to provide feedback on each of the three applications after their assigned week of using the application. The survey remained the same for each application, but the survey link was unique to the specific application for data organization. Using a Likert scale, the participants reported what they liked and disliked about each of the three applications. Participants were able to answer that they strongly agree, agree, undecided, disagree or strongly disagree for each of the questions on the survey. The following are a few examples of questions that were used in a survey to assess participants' reactions of the applications. One of the questions asked was "The application helped you to stay within your budget while grocery shopping." Another question asked was if "The application accounted for your food likes and dislikes." Participants were also asked how often they ate together as a 
family when utilizing an application. The survey that the participants completed had the same ten questions for each application (Appendix B).

\section{Statistical Analysis}

Bivariate Correlation Test were used to evaluate participants changed grocery shopping and meal prepping behaviors using each specific application. The variables of this study were the three nutrition smartphone applications and the frequency of family mealtimes eaten at home. Descriptive statistics for categorical variables were completed for all measures in this study. Significance level for all statistical analysis was set at $\mathrm{p} \leq 0.05$.

\section{Results}

\section{Total Participant Demographics}

A total of 48 potential participants that live in McLean county consented to participate in this study. Of the 48 participants, 22 individuals completed at least one of the three surveys. Out of the 22 participants, 10 completed all three surveys and were used in the final data $(21 \%$ completion). The majority of the participants were female ( $94 \%, 6 \%$ preferred not to identify as a gender) and identified as Caucasian (94\%, 6\% preferred not to specify ethnicity). The majority of participants were in the age range of 30-40 years old (37.5\%) and have a bachelor's degree (43.75\%). Seventy-five percent of the participants were married. The majority of the annual household for the participants $(50 \%)$ was $\$ 90,000$ or greater. For further demographic information refer to Table 1: Participant Demographics.

\section{Application Question Correlations}

After comparing the correlation between two questions within the same application, the study indicated the aspects within a smartphone application that are beneficial for meal planning and grocery shopping for a parent. Using SPSS Bivariate Correlation Test, the results indicated 
significant values within each application. After comparing the three applications together, participants responded that they would not continue using Shopping List Ease - Grocery List (31.25\%) and Grocery - Smart Shopping List (33.33\%) but they would continue using Mealime Meals \& Recipes (43.75\%). Looking specifically at the Mealime Meals \& Recipes, there was a strong significant positive correlation $(P=.004, \mathrm{r}=.681)$ between the continued use of the application for meal planning and grocery shopping and low time consumption. When looking at Shopping List Ease - Grocery List, there was a strong positive correlation $(P=.006, \mathrm{r}=.650)$ between user friendly navigation and continued use of this application by participants. No significant correlations were found from the Grocery - Smart Shopping List application. Refer to Table 2: Bivariate Correlation Test Results for the correlation matrix.

\section{Discussion}

The objective of this experimental study was to determine what aspects of a smartphone application were beneficial to parents' grocery shopping and meal prepping behaviors for their family. Based on published literature, it was hypothesized that a smartphone application will benefit a parent's grocery shopping and/or meal planning if the application considers budget, food preferences, and generates a grocery list. The primary results from this study indicate that a parent is more likely to continue to use a smartphone application that is beneficial to their overall meal planning for their families by providing a grocery list based off of food preferences.

\section{Smartphone Application Effects on Grocery Shopping and Meal Planning}

This study indicated an overall benefit for parents' grocery shopping and meal planning by utilizing one of the nutrition smartphone application. Two out of the three smartphone applications that were tested in this experimental study were not found to have beneficial properties for the participants. Grocery-Smart Shopping List had 46.7\% of participants indicate 
that the application was not beneficial. When looking at other questions for this application that specifically scored poorly on the Likert scale, food preferences, budgeting and adhering to the grocery were included. Shopping List Ease - Grocery List had $43.75 \%$ participants disagree that the application was beneficial. Looking at the applications that participants did not feel were beneficial to them included the applications that did not account for food preferences and did not provide a specific grocery list.

The majority of participants $(68.75 \%)$ agreed or strongly agreed that they would continue using Mealime Meal Plans and Recipes. For further application survey response information, refer to Table 3: Application Survey Results. The questions that impacted overall scoring in a positive way for this application were user-friendly navigation, low time consumption, coupon incorporation, budgeting, food preferences and sticking with the grocery list generated for them. These attributes within an application may help determine the aspects in other nutrition smartphone application that are beneficial to parents' grocery shopping and meal planning.

\section{Increased Family Mealtimes}

This study found that when a smartphone application had user-friendly navigation and low time consumption incorporated into the design, the parents were more likely to use it. A previous study found that families' food consumption was hindered based on the parents' time constraints and stress (Alm \& Olsen, 2017). If parents have an application that allows them to quickly and efficiently plan their family's meals, the family could have more meals eaten together at home. This same study also found that if there was not a meal ready to eat, parents opted for unhealthy snacks and convenience foods. Furthermore, when the parents did plan out the family’s weekly meals, a higher percentage of healthy meals were consumed (Alm \& Olsen, 
2017). When parents have a low time consumption method for meal planning for their families, the whole family could have healthier meals.

The smartphone applications from this study had a potentially positive benefit for parent's meal planning and grocery shopping. The results that were indicated in this study were supported by current literature investigating family mealtimes. When family mealtimes increase there is a decrease in food waste, stress and better time management in the kitchen. Higher level of family functioning, higher self-esteem and lower levels of depression were found in families that experienced more frequent meals together (Utter et al., 2018). Research supports the need for planned family mealtimes, but with families' busy schedules parents struggle with this task. Research supports that families with a higher percentage of family mealtimes together had lower children's body mass index (BMI) (Horning et al., 2016). Having a smartphone application that is efficient and beneficial for parents' meal planning and grocery shopping can increase family mealtimes and improve future health outcomes for their children.

\section{Grocery List Generation}

This experimental study found that participants chose only one out of the three applications to continue using after the conclusion of the study. Mealime Meal Plans and Recipes had $68.75 \%$ of participants state that they would continue using this application. This specific application also had $93.75 \%$ of participants respond that a grocery list with specific quantities was generated for them. The significant percentages found from this study can conclude that an application that generates a grocery list for the user may increase the likelihood of utilizing the application. When parents are able to stick with their grocery list and prepare planned meals, the family could have better health outcomes. 
Participants from this study, all (100\%) determined that they were the sole grocery shopper and meal planner for their families. Research supports that children learn and acquire behaviors practiced within their own families from their parents. If the children are learning from the parent that is providing the meals, the practices surrounding mealtimes should be encouraging and wholesome. Current literature also supports that pre-planned home-cooked meals were more likely to contain fruits and vegetables than unplanned meals (Fertig et al., 2019). This research can indicate the importance of having a planned grocery list from specific recipes or meals planned before going into the grocery store. When parents plan meals that contain fruits and vegetables, the children are more likely to incorporate fruits and vegetables into their own diets (Watts et al., 2017). Many research studies conclude that parents have an imperative role in their children's overall health and nutrition behaviors.

\section{Food Preferences}

The data from this study can be analyzed to understand the aspects that a nutrition smartphone application should contain to positively effect parents' behaviors surrounding their families' meals. When looking at the results from Mealime Meals and Recipes, $87.5 \%$ of participants agreed or strongly agreed that the application accounted for their food likes dislikes. This data indicates how crucial this aspect in application development is for user satisfaction. If an application takes into consideration the foods and recipes the user's family wants, the user will be more likely to utilize the application for the planning of their meals. This also can be used to account for any dietary restrictions. One of the family members could have an allergy or a food intolerance that the parent needs to exclude from the recipes. A nutrition specific smartphone application that takes into consideration the family's food preferences may benefit a parent planning meals for the family. 
Results from this study indicate that the two applications that participants would not continue using did not account for participants' food preferences. The data indicated that $68.75 \%$ of participants using Shopping List Ease - Grocery List and $79.99 \%$ of participants using Grocery-Smart Shopping List responded that this application did not account for the family's food preferences. Data suggests that an application that does not include the user's food preferences decrease the likelihood that the individual will continue using the application for meal planning.

The data analysis indicated that the favorable aspects that increased the parents' use of the nutrition smartphone application were food preferences, low-time consumption, user friendly navigation and generation of grocery list with specific food quantitates. If all of these qualities were included in the design of an application, a parent could meal plan and grocery shop efficiently and ultimately provide a positive environment for mealtimes. If a family has a positive environment surrounding mealtimes and eat together often as a family, the family's overall health status could be improved. This information can be utilized for future meal planning and grocery shopping smartphone application development.

\section{Limitations}

Within the study, limitations were acknowledged such as the overall sample size. A total of 10 participants out of the 48 that initially signed up completed all the surveys. The 10 participants that completed all three surveys gave 30 responses that could be used for the statistical data. The small number of participants could have influenced the total number of statistically significant responses. Another limitation from this study could be demographics. The lack of diversity within the study could skew the responses. The participants all stated that they were the primary grocery shopper and meal planner for their families. The purpose of the study 
was to determine behaviors of grocery shopping and meal planning, so having all participants be the primary grocery shopper for the family could have potentially skewed the results.

Another limitation within demographics was ethnicity. Out of the total participants, $94 \%$ identified as Caucasian. Having different ethnicities could have given the study a wider view on grocery shopping practices within families. All cultures and ethnicities have unique dietary practices and customs. This information would have altered the responses and data reported.

Out of the participants that gave demographical information, the majority of the annual household for the participants $(50 \%)$ was $\$ 90,000$ or greater, followed by $\$ 80,000-\$ 94,999$ $(18.75 \%)$. This information given could also skew the responses provided because higher income could correlate with less financial stress in regard to family meal supply.

To participate in this experimental study, the participants had to download three smartphone applications. A limitation of the study initially was the lack of resources of some participants to download the applications. Some participants voiced their inability to utilize the smartphone downloadable applications for the study. The initial 48 participants that enrolled in the study could have been drastically decreased to the 10 final participants due to technological difficulties.

The researcher was unable to guarantee that the smartphone applications alone influenced the participants to have an increase in family mealtimes. The lack of information given by participants determining mealtimes prior to the study could decrease the significance of the correlation between application use and increased family mealtimes. Although there is a lack of definite information in regard to the family meals and application use relationship, majority of participants $(59.5 \%)$ did report eating family meals greater than four times per week after utilizing the smartphone applications from the study. Although there is no specific data that can 
prove the exact correlation between application use and each parents' behaviors, participants reported that they would continue using the Mealime application for their grocery shopping and meal planning.

\section{Conclusion}

This experimental study intended to give information on the positive effects that a nutrition smartphone application can have on parents' grocery shopping and meal planning behavior. Overall, the results concluded that a smartphone application that generates a grocery list based off of the user's food preferences are beneficial to parents for meal planning and grocery shopping. Therefore, this information can be used in the future as a baseline to develop a nutrition smartphone application that will benefit families and their planned meals. This information can be useful for registered dietitian nutritionists who need to help patients or clients plan healthy meals for their families. The arrangement of this study and the data collected can be utilized for further research regarding smartphone applications and their correlation with user preferences. 


\section{Table 1: PARTICIPANT DEMOGRAPHICS}

\begin{tabular}{|lr|}
\hline Participant Demographics & Percentage of Participants \\
\hline Ethnicity & \\
\hline Caucasian & $100 \%$ \\
\hline Age & \\
\hline $18-25$ & $0 \%$ \\
\hline $26-30$ & $0 \%$ \\
\hline $31-35$ & $31.25 \%$ \\
\hline $36-40$ & $37.50 \%$ \\
\hline $41-45$ & $25 \%$ \\
\hline $46-50$ & $0 \%$ \\
\hline $51-55$ & $0 \%$ \\
\hline $55+$ & $0 \%$ \\
\hline Prefer not to say & $6.25 \%$ \\
\hline Gender & $0 \%$ \\
\hline Male & $93.75 \%$ \\
\hline Female & $6.25 \%$ \\
\hline Prefer not to say & $0 \%$ \\
\hline Level of Education & $0.25 \%$ \\
\hline Some High School & $6.25 \%$ \\
\hline High School & $43.75 \%$ \\
\hline Trade School & $37.50 \%$ \\
\hline Bachelor's Degree & $6.25 \%$ \\
\hline Master's Degree & $0 \%$ \\
\hline Ph.D. or higher & \\
\hline Prefer not to say & $75 \%$ \\
\hline Marital Status & $25 \%$ \\
\hline Married & $6.25 \%$ \\
\hline Unmarried & $6.25 \%$ \\
\hline Annual household Income & $6.25 \%$ \\
\hline Less than $\$ 20,000$ & $0 \%$ \\
\hline$\$ 20,000-\$ 34,999$ & \\
\hline$\$ 35,000-\$ 49,999$ & \\
\hline$\$ 50,000-\$ 64,999$ & \\
\hline$\$ 65,000-\$ 79,999$ & \\
\hline$\$ 80,000-\$ 94,999$ & \\
\hline$\$ 95,000$ or greater & \\
\hline
\end{tabular}


Table 2: BIVARIATE CORRELATION TEST RESULTS

\begin{tabular}{|c|c|c|c|}
\hline \multicolumn{4}{|c|}{ Mealime Meals \& Recipes } \\
\hline \multicolumn{4}{|c|}{ Correlations } \\
\hline & & $\begin{array}{l}\text { The selected } \\
\text { application } \\
\text { had a low } \\
\text { time } \\
\text { consumption. }\end{array}$ & $\begin{array}{l}\text { You would } \\
\text { continue to } \\
\text { use this } \\
\text { application for } \\
\text { meal } \\
\text { planning and } \\
\text { grocery } \\
\text { shopping. }\end{array}$ \\
\hline \multirow{3}{*}{$\begin{array}{l}\text { The selected application } \\
\text { had a low time } \\
\text { consumption. }\end{array}$} & Pearson Correlation & 1 & $.681^{* *}$ \\
\hline & Sig. (2-tailed) & & .004 \\
\hline & $\mathrm{N}$ & 16 & 16 \\
\hline \multirow{3}{*}{$\begin{array}{l}\text { You would continue to } \\
\text { use this application for } \\
\text { meal planning and } \\
\text { grocery shopping. }\end{array}$} & Pearson Correlation & $.681^{*}$ & 1 \\
\hline & Sig. (2-tailed) & .004 & \\
\hline & $\mathrm{N}$ & 16 & 16 \\
\hline \multicolumn{4}{|c|}{$\star \star$. Correlation is significant at the 0.01 level (2-tailed). } \\
\hline \multicolumn{4}{|c|}{ Shopping List Ease - Grocery List } \\
\hline \multicolumn{4}{|c|}{ Correlations } \\
\hline & & $\begin{array}{l}\text { The selected } \\
\text { application } \\
\text { had user- } \\
\text { friendly } \\
\text { navigation. }\end{array}$ & $\begin{array}{l}\text { You would } \\
\text { continue to } \\
\text { use this } \\
\text { application for } \\
\text { meal } \\
\text { planning and } \\
\text { grocery } \\
\text { shopping. }\end{array}$ \\
\hline \multirow{3}{*}{$\begin{array}{l}\text { The selected application } \\
\text { had user-friendly } \\
\text { navigation. }\end{array}$} & Pearson Correlation & 1 & $.650^{*}$ \\
\hline & Sig. (2-tailed) & & .006 \\
\hline & $N$ & 16 & 16 \\
\hline \multirow{3}{*}{$\begin{array}{l}\text { You would continue to } \\
\text { use this application for } \\
\text { meal planning and } \\
\text { grocery shopping. }\end{array}$} & Pearson Correlation & $.650^{* *}$ & 1 \\
\hline & Sig. (2-tailed) & .006 & \\
\hline & $\mathrm{N}$ & 16 & 16 \\
\hline
\end{tabular}


Table 3: APPLICATION SURVEY RESULTS

\begin{tabular}{|c|c|c|c|}
\hline Survey Questions & $\begin{array}{c}\text { Shopping List Ease - } \\
\text { Grocery List }\end{array}$ & $\begin{array}{c}\text { Grocery - Smart } \\
\text { Shopping List }\end{array}$ & $\begin{array}{c}\text { Mealime Meal Plans } \\
\text { and Recipes }\end{array}$ \\
\hline $\begin{array}{l}\text { 1. The selected } \\
\text { application had user- } \\
\text { friendly navigation }\end{array}$ & Agree $-50 \%$ & Agree $-73.33 \%$ & Agree $-37.5 \%$ \\
\hline $\begin{array}{l}\text { 2. The selected } \\
\text { application had a low } \\
\text { time consumption }\end{array}$ & Agree $-31.25 \%$ & Agree $-53.33 \%$ & Agree $-62.5 \%$ \\
\hline $\begin{array}{l}\text { 3. The selected } \\
\text { application was } \\
\text { beneficial to your } \\
\text { grocery shopping and/or } \\
\text { planning of meals. }\end{array}$ & Disagree $-43.75 \%$ & Disagree - $46.67 \%$ & Strongly Agree - $50 \%$ \\
\hline $\begin{array}{l}\text { 4. The coupon aspect of } \\
\text { the application was } \\
\text { valuable to your grocery } \\
\text { shopping. }\end{array}$ & Undecided $-62.5 \%$ & Undecided - $53.33 \%$ & Undecided - $62.5 \%$ \\
\hline $\begin{array}{l}\text { 5. The selected } \\
\text { application helped you to } \\
\text { stay within your budget } \\
\text { while grocery shopping. }\end{array}$ & Agree - $50 \%$ & Agree $-33.33 \%$ & Undecided - $37.5 \%$ \\
\hline $\begin{array}{l}\text { 6. The selected } \\
\text { application generate a } \\
\text { grocery list with specific } \\
\text { quantities. }\end{array}$ & Agree $-50 \%$ & Agree $-73.33 \%$ & $\begin{array}{c}\text { Strongly Agree - } \\
62.5 \%\end{array}$ \\
\hline $\begin{array}{l}\text { 7. The selected } \\
\text { application accounted for } \\
\text { your food likes and } \\
\text { dislikes. }\end{array}$ & Disagree $-37.5 \%$ & $\begin{array}{c}\text { Disagree }-33.33 \% \\
\text { Undecided }-33.33 \%\end{array}$ & Strongly Agree - $50 \%$ \\
\hline $\begin{array}{l}\text { 8. While grocery } \\
\text { shopping, you strayed } \\
\text { away from the grocery } \\
\text { list that the application } \\
\text { created for you. }\end{array}$ & Agree $-37.5 \%$ & Agree $-46.67 \%$ & Disagree $-37.5 \%$ \\
\hline
\end{tabular}




\begin{tabular}{|l|c|c|c|}
\hline $\begin{array}{l}\text { 9. You would continue to } \\
\text { use this application for } \\
\text { meal planning and } \\
\text { grocery shopping. }\end{array}$ & Disagree - 31.25\% & $\begin{array}{c}\text { Strongly Disagree - } \\
33.33 \%\end{array}$ & Agree - 43.75\% \\
\hline $\begin{array}{l}\text { 10. How many children } \\
\text { were you preparing food } \\
\text { for in the evenings this } \\
\text { week? }\end{array}$ & $\begin{array}{c}\text { Two Children - } \\
62.5 \%\end{array}$ & $\begin{array}{c}\text { Two Children - } \\
66.67 \%\end{array}$ & $\begin{array}{c}\text { Two Children - } \\
68.75 \%\end{array}$ \\
\hline $\begin{array}{l}\text { 11. How often did you } \\
\text { go to the grocery store } \\
\text { while using this } \\
\text { application? }\end{array}$ & One Time- 62.5\% & One Time-60\% & One Time-50\% \\
\hline $\begin{array}{l}\text { 12. How many times did } \\
\text { you eat evening meal } \\
\text { together as a family this } \\
\text { week? }\end{array}$ & $\begin{array}{c}\text { Two Times - 18.75\% } \\
\text { Four Times - 18.75\% }\end{array}$ & $\begin{array}{c}\text { Three Times - } \\
26.67 \%\end{array}$ & Five Times - 31.25\% $26.67 \%$ \\
\hline
\end{tabular}




\section{CHAPTER II: EXTENDED LITERATURE REVIEW}

The purpose of this literature review is to explore pre-existing literature and to increase understanding of previous research findings. This review will display gaps in literature that evaluate the effect of smartphone applications on parent's grocery shopping and meal planning behaviors.

\section{Parents and Meal Planning}

A couple could have a functioning routine including eating dinner together every night. They have time after each of them return home from work to grocery shop and prepare a meal. When the couple decides to start a family, their schedule now has to incorporate caring for the child. With the addition of a child, the couple may not have as much time to prepare a meal. This cycle may continue and as the child ages, or the family adds another child to the family, the schedule of the family as a whole becomes saturated. This could lead to a decrease in meal planning and frequency of family mealtimes. A study researched how families' food consumption was hindered based on parents' time constraints and stress (Alm et al., 2017). Children in the family were asked to document dinner with a picture. The children were supposed to include the food, the people they shared the meal with, the person that prepared the meal, and the person that did the grocery shopping. The children were then interviewed oneweek post-photo documentation (Alm et al., 2017). Researchers found that in every family the parents were concerned with planning and preparing healthy meals for their families. Another common concern was the children's involvement in athletics. The more activities the children were involved in, the more difficult meal planning was for the parents. The study also found that when there was not a meal ready to eat, the parents opted for unhealthy snacks and convenience foods (Alm et al., 2017). However, the most notable finding was that the parents who planned 
their meals weekly showed a higher percentage of healthy family meals. The families that did not plan ahead went to the grocery store more frequently in a week and left the grocery store with a higher amount of nutritionally low-quality foods. Ultimately, this study found that the children adopted the parent's food habits, for better or worse (Alm et al., 2017). When a family prioritizes home-cooked meals, not only could parent's stress decrease, but the likelihood of the children carrying nutritious dietary habits into adulthood could increase.

Though parents may opt to not cook meals at home due to a busy schedule, they also may opt for convenience and fast food options due to the lack of confidence of planning and preparing the meals. A study that looked at how meal planning's relationship to food variety and diet quality found that parents with few cooking skills are more likely to opt for a convenience meal (Horst, Brunner \& Siegrist, 2011). The study investigated the relationship between chronic disease risk and dietary behavior. The participants completed a questionnaire assessing dietary intake, physical activity, anthropometrics, lifestyle, socioeconomic conditions, and health status. Meal planning practices were assessed with an additional questionnaire. Some questions included grocery shopping habits and practices, cooking skills, and meal planning. The participants completed the same questionnaire post-study. The study found that meal planning was associated with higher-quality nutritional food choices and also a larger variety of food intake. In addition, meal planning was associated with lower obesity and overweight rates in individuals. When parents plan their meals, it will decrease trips to the grocery store freeing up time in a busy week's schedule. Planned meals will also increase food variety which could lead to increased nutrition quality. This gives children an increased chance of a healthy adolescent diet (Ducrot, Mejean, Aroumougame, Ibanez, Alles, Kesse-Guyot \& Peneau, 2017). 
Not only do parents have a large influence on their child's food intake, they also have control over the environment where the meal takes place. The nutritious quality of the meal is important, but the environment of the meal is just as important. If a child spends every meal in front of the television, they will continue this habit as they age and may be passed to their children. A study researched the effects of a parent's time spent eating with their children and the child's dietary intake. The families in this study kept diaries for three days to investigate mealtimes and activities within the household. The children also kept a diary. They were asked to record the time that they ate with their families or if they ate alone. The study concluded that parental inclusion in a child's mealtime positively impacted the child's nutrition. When a parent prepares a meal at home for the family, the child is involved in the preparation, sees the parents cook, and the quality of the food is often superior to convenience or fast food options (Chen, Moser \& Nayga, 2015).

Parents' involvement in their child's nutrition can largely impact the future health of the child. Nearly $25 \%$ of preschool-aged children are overweight or obese (Ogden, Carroll, Kit \& Flegal, 2014). Educating parents on meal planning and healthy eating behaviors models positive behavior for their children. Dietitians have the ability to educate families on the importance of incorporating healthier nutrition habits to aid childhood obesity.

Childhood obesity could be stemmed from multiple factors including families, environment and socioeconomic status. A study investigated what resources would improve the nutritional habits of low-income families to increase their frequency of family meals and quality of food. The study focused on cultivating the ability for parents to implement family mealtimes to prevent obesity and identifying if lack of resources prevented family mealtimes. The participants were given cookware, healthy recipes, preparation techniques, and social support 
elements. Family meal frequency was assessed halfway through the intervention period. The children's dietary quality, parents' cooking self-efficacy, barriers to family meals, mealtime resources, and mealtime climate were all investigated. The study found that providing ample cooking resources to low-income families is a significant implication to improving dietary habits within these families.

When given the proper resources to create a positive family mealtime environment, it is more likely that the parents will follow through with a plan. When a parent plans out the meals for the week and goes to the grocery store knowing what foods to purchase, they will be more likely to prepare that meal with the necessary ingredients. If a parent is rushed one night after work and does not have a meal prepared, they may opt for a fast food option for the family. This study shows that planning and having the necessary tools to prepare home-cooked family meals is necessary (Brophy-Herb, Horodynski, Contreras, Kerver, Kaciroti, Stein \& Lumeng, 2017). With childhood obesity rates climbing, family mealtimes need to be further explored.

\section{Lack of Meal Planning Results in Food Waste in Families}

Neglecting to plan meals could lead to increased food waste within the home. Parents who do not meal plan ahead of time may find themselves aimlessly wandering around the grocery store, purchasing items that do not go together well. Globally, around one third of the food that is produced for human purchasing and consumption is wasted (Morone, Koutinas, Gathergood, Arshadi \& Matharu, 2019). One study investigated household behaviors to determine where food waste was stemming from. Researchers sent a questionnaire to families to assess their habits as a whole. The study found that eating out frequently and buying convenience foods increased the food wasted within the household (Mattar, Abiad, Chalak, Diab \& Hassan, 2018). This illustrates the importance of meal planning in families; if a parent does not have a 
plan when grocery shopping, they will be more likely to purchase items that do not make a logical meal, opt to eat out, and then waste the groceries.

When parents enter a grocery store without a plan, not only can food waste increase but unplanned spending can increase. In the United States, 40 million people are considered "food insecure," meaning they have limited or no access to adequate and healthy food options due to a lack of income (Journal of Law, Medicine \& Ethics, 2019). Some of these families are not only food insecure but are also wasting up to $40 \%$ of their food supply (Gunders et al., 2019). An organized meal plan and grocery list allows the family to stay within their budget and prevent food waste.

Creating a meal plan as a family allows the parents to stay on track with their grocery budget, while allowing families to eat foods they all enjoy. In addition, grocery planning means less trips to the store and more time to prepare home-cooked meals for their family (Gee, Davidson, Speetles \& Webber, 2019). The top indicators when applying a household production model in regard to food waste were raw foods, income, and overall time constraint (Lusk \& Ellison, 2017). This study showed budgeting for things on a set grocery list could decrease overall food waste within that family. In addition to all of these indicators, lack of cooking skills and/or knowledge can also impact food waste within the family. If the parent is unsure of preparation methods, they are more likely to not prepare the meal. Having a set list of instructions for the meal will increase the likelihood of the parent preparing the meal.

\section{Family Mealtimes}

This literature review has discussed the many positive outcomes to meal planning: decreased food waste, staying within a budget, decreased stress and better time management in the kitchen. There may also be a positive correlation of meals spent as a family and the wellbeing 
of the family members. A survey was sent out to families to report on their own family mealtimes. Models and indicators were used to determine the frequency of the family meals, nutritional aspects of the meals, and also social and emotional wellbeing of the family members surrounding the mealtimes. The research showed that there was a positive association with better mental health of the parents and also a higher consumption of fruits and vegetables when the families ate together (Utter, Larson, Berge, Eisenberg, Fulkerson \& Neumark-Sztainer, 2018). Higher level of family functioning, higher self-esteem and lower levels of depression were all found when families had frequent mealtimes together. It is known that family mealtimes can impact a child's weight status and future health, but meals spent together as a family can also impact the mental and emotional health as well.

Despite the benefits, some families struggle to find time within their days for meal planning. Some families need extra guidance to figure out how to plan and fit in mealtimes. The objective of a 2017 study was to examine the correlation of various parenting practices and adolescent fruit and vegetable intake depending on frequency of family meals spent together. Following a survey, the study showed that frequent family meals with easily accessible fruits and vegetables led to an increased adolescent fruit and vegetable intake (Watts, Loth, Berge, Larson \& Neumark-Sztainer, 2017). The children pick up these habits and carry them into adulthood. They will mimic what they are used to in their own families. If a parent decides to meal plan with fruits and vegetables, the child will be more likely to choose a fruit or vegetable when it is their turn to decide on their meals. In addition to the specific foods that the parents decide to prepare, the environment in which they prepare the meal and enjoy the meal matter as well. The outcome of the child's health can closely be related to how the parents decide to have meals (Watts et al., 2017). 
A parent must consider many different factors when deciding how to structure a meal and the environment in which they eat. Income is one factor that may greatly affect how a parent meal plans, prepares the meal, and the meal environment. If a parent feels stressed over finances, preparing home-cooked meals for their family may not be a top priority (Kasper, Ball, Halverson, Miller, Appugliese, Lumeng \& Peterson, 2019). However, research shows how important family meals are to a child's future health. One study looked at mealtime characteristics and how they affect low-income families. The four characteristics that the study included were eating at a table, family-style meal serving, no television usage during mealtime, and parent involvement. Each of these characteristics play a role in the overall functionality of the meal. The study found that when each of the four characteristics were met, the family meals were associated with healthier foods served (Kasper et al., 2019). This research showed that when the environment is set a certain way, the family makes healthier choices. The whole family must eat together at a designated table, turn off electronic distractions, and serve the meal on a plate in proper portion sizes, then healthier food options may be chosen. Eating is habitual. When eating habits are centered around positive family time, it will only make the habit correlate to a healthier lifestyle for the whole family (Kasper et al., 2019).

Part of this positive environment cultivation is how the meal is prepared. A research study investigated if the source of the family meal effected the overall meal. This study investigated if a family's nutrition differed between home-cooked meals and pre-prepared meals, such as frozen dinners. The study examined multiple families that practiced both these techniques (Fertig, Loth, Trofholz, Tate, Miner, Neumark-Sztainer \& Berge, 2019). Researchers followed 150 families with children aged five to seven years old. All of the families reported that home-cooked meals were more likely to contain fruits and vegetables than pre-prepared meals. 
This conclusion shows that encouraging families to prepare meals together within the home will increase consumption of nutritionally dense foods such as fruits and vegetables.

When eating as a family, there are multiple goals that could be implemented to improve the meal environment. A research study looked at the goals that should be incorporated into family meals to determine if there was a correlation between how often the family ate together and the children's dietary intake. The study recorded 12 months' worth of data including children participants ages eight to twelve. The aim of the study was to implement a set of mealtime goals for parents. The goals included: nutrition education, meal planning, cooking skill development, and reduced screen time. The results showed the parents who were involved with nutrition education had higher self-efficacy scores for identifying portion sizes of their family's meals. As a result of the nutrition education, the children were less likely to consume a sugarsweetened beverage daily than the control children group (Fulkerson, Friend, Flattum, Horning, Draxten, Neumark-Sztainer \& Kubik, 2015). In conclusion, this study shows the importance of nutrition education and implementation of nutrition focused goals within families to improve the nutrition intake of the children. The intervention of the nutrition education improved two nutrition-related behaviors within the families. This information can be used to implement future nutrition education within families.

\section{Parent Grocery Shopping Behaviors}

Research has shown that family meal frequency and meal environment affect the quality of nutrition within the home. In addition, researchers investigated if the behaviors of the parents within the grocery store affect the nutrition choices and quality of nutrition of the family as well. A study investigated children's influence on the parent's behaviors within the grocery store and how bringing children into the grocery store affects what foods are purchased. An electronic 
survey was used to identify the parent's behaviors. The study examined the way the child asked for a food item, the types of food items requested, the level of impact the child has on purchasing items, and also the child's product preference. The study concluded that a strong correlation of how the child asked for the food item influenced the parent's decision (Balcarová, Pokorná \& Pilar, 2014). Verbally asking was more likely to influence the parent's decision over the child grabbing for the item. The parents were also more likely to purchase lunch items for the child over other meals. In addition, products with pictures, bright colors, or familiar characters were more often requested. If a parent did not have a set list that they planned to purchase, the child was more able to persuade the parent to purchase food items that were outside of the necessary food items. Ultimately, bringing the child along to grocery shop could impact the foods purchased. Similar to mealtime and meal prep time behavior, grocery store behavior can impact a family’s nutrition quality (Balcarová et al., 2014).

This grocery store behavior is partially due to the parent-child relationship. The child has their own persuasion techniques when in the grocery store. One research study looked at healthfulness of parental responses to child food purchasing requests as well as parent's "resist strategies." The participants were parents who were the primary food purchaser and had children aged two to six years old. The children in the study made a total of 222 total food purchasing requests with an average of 5.7 requests per shopping trip per child. The study found that parents yielded to $45.5 \%$ of the total food purchasing requests of the children. The most common resist strategies included saying "no" and explaining to the child why they could not have the requested item (Calloway, Ranjit, Sweitzer, Roberts-Gray, Romo-Palafox, McInnis \& Briley, 2016). The study found that a moderate amount of conflict occurred when the child was denied their food purchasing request. This study clearly showed the impact that children have on the 
parent's purchasing behaviors within the grocery store. Many parents may yield to their child's request simply to avoid conflict in the grocery store. Determining healthy nutritional habits within a family can be initiated while in the grocery store. If the child has the majority of the say of what foods are brought into the household, the family may opt for less nutritionally dense foods. Thus, when grocery shopping, parents must be cautious about how much say children have in what the family purchases and ultimately consumes.

There are many patterns within specific families that could determine their nutrition habits and quality of food. One study investigated the food purchasing patterns while grocery shopping and the association of diet quality. The methods of this study included identifying all food purchases from 13,125 households. Each of the foods were split into a category that had a corresponding nutrient guide. This guide was used to determine the quality of the foods chosen. Food items were divided into three categories including natural, processed, and traditional. The results of the study found that a higher purchasing average of natural foods was found in families with higher socioeconomic standings (Thiele, Peltner, Richter \& Mensink, 2017). These results showed that families with a higher education and income status are more likely to choose nutrient dense foods for their families as opposed to lower income families choosing processed foods. Not all families can improve their income status, but if families had the opportunity to increase their nutrition education, families can incorporate healthier and more nutrient dense foods within their families. Dietitians have the ability to educate families on all education levels to improve the overall health status of that family.

\section{Home-Cooked Family Meals and Children's Health}

Childhood obesity is growing at an alarmingly high rate. A study investigated if there are relationships between youth weight status, dietary intake, and psychological outcomes. This 
study looked specifically at family mealtime frequencies. Data was collected from diet recalls, interviews, and psychological surveys. The study found that the families with a higher percentage of family mealtimes together had lower children's body mass index (BMI) (Horning, Fulkerson, Friend \& Neumark-Sztainer, 2016). Family mealtime has many definitions, but the research shows that spending time eating as a family within the home does correlate with the BMI status of the children (Horning et al., 2016). If a child's weight status and future health outcomes could be positively affected by the frequency that a family eats a meal together, then creating a strategy to create a positive mealtime together should be implemented. Children inherit nutrition habits from their family members. Creating good mealtime habits could set the child up for a healthier future.

Research shows that eating meals together as a family is important for a child's future health. One study researched the association between the healthfulness of foods served at the family mealtimes and the overall dietary intake of the child. This study was observational and included low-income, minority families. Three 24-hour diet recalls were completed on the child's intake. Scores accounted for whole fruit, $100 \%$ fruit juice, vegetables, dark green vegetables, dairy, protein, added sugars, and high sodium-foods. The results found that the majority of the foods served at family mealtimes were protein and high-sodium food sources. Nearly half of the meals had an added-sugar food, such as soda or a dessert. Few meals incorporated whole fruit, dark vegetables, or 100\% fruit juice (Trofholz, Tate, Draxten, Rowley, Schulte, Neumark-Sztainer \& Berge, 2017). This study found that many family meals do not contain the proper dietary intake that a child should have in their youth. Mealtime together as a family is important, but incorporating whole fruits, dark green vegetables, and less sugar-added items is equally as important for the future health of the child. 
Health outcomes of children can be correlated with regular family mealtimes. Children who eat regular family meals together are less likely to have an increased risk-related outcome in adolescence, including alcohol, tobacco and other drug use (Eisenberg, Olson, NeumarkSztainer, Story \& Bearinger, 2004). One study looked beyond the frequency of meals to investigate the dimensions of family meals. The goal of this study was to provide deeper context to what family meals mean and the importance of meals for children's health. Qualitative methods were used to survey families and their interactions at meals. The researchers looked at language and vocabulary used and overall environment. Participants were asked questions about family meals, parent-child relationship, family general practices, child's weekly activities, and specific foods served at meals. The research found that even when the children did not particularly enjoy the meal itself, they enjoyed the time spent as a family. The children viewed the mealtime as a set time where they knew they would be fed but also a time to spend as a family together. The parents viewed mealtimes as an opportunity to have deeper conversations with the family and teach about their values as a family (Skeer, Sonneville, Deshpande, Goodridge \& Folta, 2018). Many factors affect a child's future health. Between the specific foods served at meals, the environment at the meal, and the time spent together as a family, mealtimes can have a positive impact on the overall well-being of the children.

\section{Conclusion}

This review of published literature supports why a smartphone application that encourages positive grocery shopping and meal planning behaviors in parents can be beneficial to the family's overall health. Literature states that the healthy behaviors that children learn in their childhood immensely impact their future health outcomes. Literature shows that children take their parent's meal behaviors that are implemented in the family with them as the age. This 
research data could be beneficial for future research for nutrition smartphone application development. Research has shown that eating nutritious meals as a family benefits a child's development in many ways. 


\section{REFERENCES}

Alm, S., \& Olsen, S. O. (2017). Coping with time pressure and stress: Consequences for families' food consumption. Journal of Consumer Policy, 40(1), 105-123.

Balcarová, T., Pokorná, J., \& Pilar, L. (2014). The influence of children on the parents buying behavior: Food purchase in the czech republic. Agris On-Line Papers in Economics \& Informatics, 6(2), 11-19.

Brophy-Herb, H. E., Horodynski, M., Contreras, D., Kerver, J., Kaciroti, N., Stein, M., Lumeng, J. C. (2017). Effectiveness of differing levels of support for family meals on obesity prevention among head start preschoolers: The simply dinner study. $B M C$ Public Health, 17(1), 1-11.

Calloway, E., Ranjit, N., Sweitzer, S., Roberts-Gray, C., Romo-Palafox, M., McInnis, K., \& Briley, M. (2016). Exploratory cross-sectional study of factors associated with the healthfulness of parental responses to child food purchasing requests. Maternal \& Child Health Journal, 20(8), 1569-1577.

Chen, S. E., Moser, A., \& Nayga, R. M., Jr. (2015). Too busy to eat with the kids? Parental work and children's eating. Applied Economic Perspectives and Policy, 37(3), 347-377.

D. Gunders et al., Wasted: How america is losing up to 40 Percent of its food from farm to fork to landfill. Natural Resource Defense Council.

Ducrot, P., Mejean, C., Aroumougame, V., Ibanez, G., Alles, B., Kesse-Guyot, E., Peneau, S. (n.d.). Meal planning is associated with food variety, diet quality and body weight status in a large sample of french adults. International Journal of Behavioral Nutrition and Physical Activity. 
Eisenberg, M. E., Olson, R. E., Neumark-Sztainer, D., Story, M., \& Bearinger, L. H. (2004). Correlations between family meals and psychosocial well-being among adolescents. Archives of Pediatric and Adolescent Medicine, 158, 792-796.

Fertig, A. R., Loth, K. A., Trofholz, A. C., Tate, A. D., Miner, M., Neumark-Sztainer, D., \& Berge, J. M. (2019). Compared to pre-prepared meals, fully and partly home-cooked meals in diverse families with young children are more likely to include nutritious ingredients. Journal of the Academy of Nutrition \& Dietetics, 119(5), 818-830.

Food waste: Addressing our 160-billion-pound public health challenge with policy and business interventions. (2019). Journal of Law, Medicine \& Ethics, 47, 100-103.

Fulkerson, J. A., Friend, S., Flattum, C., Horning, M., Draxten, M., Neumark-Sztainer, D., Kubik, M. Y. (2015). Promoting healthful family meals to prevent obesity: Home plus, a randomized controlled trial. International Journal of Behavioral Nutrition \& Physical Activity. 12, 1-12.

Gee, I. M., Davidson, F. T., Speetles, B. L., \& Webber, M. E. (2019). Deliver me from food waste: Model framework for comparing the energy use of meal-kit delivery and groceries. Journal of Cleaner Production, 236, 117587.

Handley, L. (2019, January 24). Nearly three quarters of the world will use just their smartphones to access the internet by 2025 .

Horning, M. L., Fulkerson, J. A., Friend, S. E., \& Neumark-Sztainer, D. (2016). Associations among nine family dinner frequency measures and child weight, dietary, and psychosocial outcomes. Journal of the Academy of Nutrition and Dietetics. 116(6), 991-999. 
Jieun Kim, \& Hyunjung Lim. (2019). Nutritional management in childhood obesity. Journal of Obesity \& Metabolic Syndrome, 28(4), 225-235.

Kasper, N., Ball, S. C., Halverson, K., Miller, A. L., Appugliese, D., Lumeng, J. C., \& Peterson, K. E. (2019). Deconstructing the family meal: Are characteristics of the mealtime environment associated with the healthfulness of meals served? Journal of the Academy of Nutrition and Dietetics.

Lusk, J. L., \& Ellison, B. (2017). A note on modelling household food waste behaviour. Applied Economics Letters, 24(16-18), 1199-1202.

Mattar, L., Abiad, M. G., Chalak, A., Diab, M., \& Hassan, H. (2018). Attitudes and behaviors shaping household food waste generation: Lessons from lebanon. Journal of Cleaner Production, 198, 1219-1223.

Morone, P., Koutinas, A., Gathergood, N., Arshadi, M., \& Matharu, A. (2019). Food waste: Challenges and opportunities for enhancing the emerging bioeconomy. Journal of Cleaner Production, 221, 10-16.

Olshansky, S. J., Douglas J. Passaro, Ronald C. Hershow, Jennifer Layden, Bruce A. Carnes, Jacob Brody, Leonard Hayflick, Robert N. Butler, David B. Allison, and David S. Ludwig (2005), "A potential decline in life expectancy in the united states in the 21st century," New England Journal of Medicine, 352(11), 1138-45.

Ogden CL, Carroll MD, Kit BK, Flegal KM. Prevalence of childhood and adult obesity in the United States, 2011-2012. JAMA.

Richins, Marsha L. and Lan Nguyen Chaplin (2015), "Material parenting: How the use of goods in parenting fosters materialism in the next generation," Journal of Consumer Research, 41(6), 1333-57. 
Skeer, M. R., Sonneville, K. R., Deshpande, B. R., Goodridge, M. C., \& Folta, S. C. (2018). Going beyond frequency: A qualitative study to explore new dimensions for the measurement of family meals. Journal of Child \& Family Studies, 27(4), 1075-1087.

Thiele, S., Peltner, J., Richter, A., \& Mensink, G. B. M. (2017). Food purchase patterns: Empirical identification and analysis of their association with diet quality, socioeconomic factors, and attitudes. Nutrition Journal, 16, 1-14.

Trofholz, A. C., Tate, A. D., Draxten, M. L., Rowley, S. S., Schulte, A. K., Neumark-Sztainer, D., Berge, J. M. (2017). What's being served for dinner? An exploratory investigation of the associations between the healthfulness of family meals and child dietary intake. Journal of the Academy of Nutrition and Dietetics, 117(1), 102-109.

Utter, J., Larson, N., Berge, J. M., Eisenberg, M. E., Fulkerson, J. A., \& Neumark-Sztainer, D. (2018). Family meals among parents: Associations with nutritional, social and emotional wellbeing. Preventive Medicine, 113, 7-12.

Van der Horst K, Brunner TA, Siegrist M. Ready-meal consumption: Associations with weight status and cooking skills. Public Health Nutrition. 2011; 14:239-45.

Walton, K., Kleinman, K. P., Rifas-Shiman, S. L., Horton, N. J., Gillman, M. W., Field, A. E., Haines, J. (2016). Secular trends in family dinner frequency among adolescents. BMC Research Notes, 9, 1-5.

Watts, A. W., Loth, K., Berge, J. M., Larson, N., \& Neumark-Sztainer, D. (2017). No time for family meals? Parenting practices associated with adolescent fruit and vegetable intake when family meals are not an option. Journal of the Academy of Nutrition \& Dietetics, $117(5), 707-714$. 
Yakovenko, V., Henn, L., Bettendorf, M., Zelinska, N., Soloviova, G., Hoffmann, G. F., \& Grulich-Henn, J. (2019). Risk factors for childhood overweight and obesity in ukraine and germany. Journal of Clinical Research in Pediatric Endocrinology, 11(3), 247-252. 


\section{APPENDIX A: SMARTPHONE APPLICATION CRITERIA}

\begin{tabular}{|l|l|l|l|}
\hline \multicolumn{1}{|c|}{ Application name: } & Yes & No & \\
\hline Does it cost? & & & \\
\hline Does it ask for a budget? & & & \\
\hline Does it ask for location? & & & \\
\hline Does it compile coupons in a location? & & & \\
\hline Are coupons organized by store? & & & \\
\hline Are coupons organized by type of food? & & & \\
\hline Is there a weekly meal planner? & & & \\
\hline Is there a food preference list for each food group? & & & \\
\hline Is there an autogenerated grocery list from the preference list? & & & \\
\hline Does the grocery list have the quantity of item needed? & & & \\
\hline Does it autogenerate recipes for the grocery list? & & & \\
\hline Do the recipes have specific directions for preperation? & & & \\
\hline Does the grocery list fall within the budget allotted? & & & \\
\hline
\end{tabular}




\section{APPENDIX B: SMARTPHONE APPLICATION PARTICIPANT SURVEY}

Q2 The selected application had user-friendly navigation.

Q3 The selected application had a low time consumption.

Q4 The application was beneficial to your grocery shopping and/or planning of meals.

Q5 The coupon aspect of the application was valuable to your grocery shopping.

Q6 The application helped you to stay within your budget while grocery shopping.

Q7 The application generated a grocery list with specific quantities.

Q8 The application accounted for your food likes and dislikes.

Q9 While grocery shopping, you strayed away from the grocery list that the application created for you.

Q10 You would continue to use this application for meal planning and grocery shopping.

Q11 How many children were you preparing food for in the evenings this week?

Q12 How often did you go to the grocery store while using this application?

Q13 How many times did you eat the evening meal together as a family this week? 